\title{
The synthesis of carbohydrate-derived acylsilanes and their intramolecular free radical cyclizations with the formation of polyoxygenated cyclopentanes
}

\author{
Che-Chien Chang, Yu-Hsien Kuo, Yeun-Min Tsai * \\ Department of Chemistry, National Taiwan University, Taipei, Taiwan 106, ROC
}

\section{A R T I C L E I N F O}

\section{Article history:}

Received 6 January 2009

Revised 14 March 2009

Accepted 6 April 2009

Available online 14 April 2009

Keywords:

Acylsilane

Radical cyclization

Polyoxygenated cyclopentanes

\begin{abstract}
A B S T R A C T
A convenient way for the synthesis of acylsilanes from arabinose, lyxose, and ribose is developed. All the chiral centers of the carbohydrate templates are conserved, and only the reducing end is transformed into the acylsilane functional group. The non-reducing end of the templates can be converted into a bromide. These bromo acylsilanes undergo efficient intramolecular radical cyclizations to give polyoxygenated cyclopentanes.
\end{abstract}

(c) 2009 Elsevier Ltd. All rights reserved.
Acylsilane is a useful functionality which has attracted the attentions of synthetic chemists. ${ }^{1}$ The presence of silyl group on the carbonyl not only enhances the reactivity of a carbonyl but also becomes a useful handle for additional transformations.

Several years ago we have initiated a project to study the intramolecular radical cyclizations involving acylsilanes. ${ }^{2}$ As shown in Scheme 1, intramolecular radical cyclization of acylsilane $\mathbf{1}$ gives a cyclized alkoxy radical intermediate $\mathbf{2}$ with a silyl group attached at the $\beta$-position of the radical. A facile radical-Brook rearrangement $^{3,4}$ successfully drives the reaction toward the formation of a silyloxy-substituted radical 3. In contrast, similar radical cyclizations involving formyl group are known to be reversible processes in favor of the acyclic radicals. ${ }^{5}$ Therefore, the special feature of the radical cyclizations of acylsilanes made this type of reaction a useful method in the preparation of cyclic alcohols. ${ }^{6}$

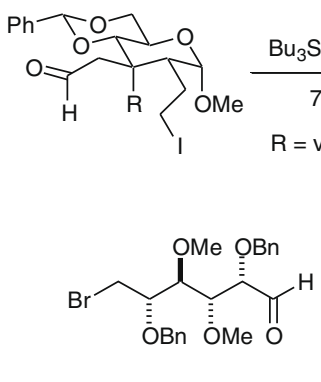

4

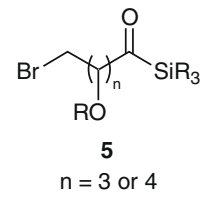

\footnotetext{
* Corresponding author. Tel.: +886 2 33661651; fax: +886223636359.

E-mail address: ymtsai@ntu.edu.tw (Y.-M. Tsai).
}

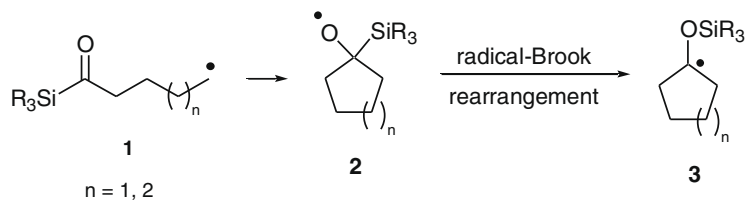

Scheme 1.

Carbohydrates are unique sources of chirality in nature and have been extensively used as building blocks for the synthesis of enantiomerically pure and highly oxygenated derivatives. ${ }^{7}$ In particular, the conversion of carbohydrates to carbocycles is an area that has been extensively studied. ${ }^{8}$ Fraiser-Reid and co-workers demonstrated several successful carbohydrate-based free radical cyclizations in which aldehyde groups served as the radical acceptor (Eq. 1). ${ }^{9}$ In these cyclizations, the $\omega$-formylalkyl radicals are immobilized by fusing with a pyranoside ring. However, aldehydes that carry carbohydrate skeleton, such as bromide $\mathbf{4}$, are not good substrates for radical cyclizations. ${ }^{\text {ff }}$ Thus there is a need to examine whether acylsilane $\mathbf{5}$ can be suitable substrate for this purpose. Herein we wish to report our synthesis of some pentose-derived acylsilanes and the study of their intramolecular radical cyclizations.

Preparation of carbohydrate-derived acylsilanes has been reported by Plantier-Royon and Portella ${ }^{10}$ using the 2-silylated1,3-dithiane approach developed by Brook ${ }^{11}$ and Corey. ${ }^{12}$ In this approach, all the chiral centers of the carbohydrate substrates are retained and the carbon skeleton is extended by one. However, the $\alpha$-position of the resulting acylsilanes cannot have a hydroxyl or alkoxy substituent. Although several reports about the construction 
of $\alpha$-oxy acylsilanes were known, none of these methods employed carbohydrate starting material directly. ${ }^{13}$ We decided to explore the possibility of adding a silyl anion to the carbonyl end of a carbohydrate to generate an $\alpha$-silyl alcohol. ${ }^{14}$ The resulting $\alpha$-silyl alcohol can then be oxidized to give an acylsilane with the desired carbohydrate skeleton.

As shown in Scheme 2, aldehyde $\mathbf{6} \mathbf{a}^{15}$ derived from arabinose with all the secondary hydroxyl groups protected by benzyl groups did not react with methyldiphenylsilyl lithium or the corresponding silyl cuprate. With the hypothesis that this aldehyde is quite sterically hindered due to the presence of adjacent bulky substituents, we switched to the methylated analog $\mathbf{6 b} .{ }^{16}$ Indeed, aldehyde 6b reacted with methyldiphenylsilyl lithium and gave $\alpha$-silyl alcohol 7 in 46\% yield. By using the less basic lithium bis(methyldiphenylsilyl)cuprate, the yield of $\alpha$-silyl alcohol 7 was improved to $62 \%$.

The trityl group in alcohol $\mathbf{7}$ was removed in a mixture of THF and methanol in the presence of $p$-toluenesulfonic acid. The primary hydroxyl group of the resulting diol 8a was converted to a methanesulfonate $\mathbf{8 b}$. This material was then oxidized using the Swern method ${ }^{17}$ to give acylsilane $8 \mathrm{c}$ in $45 \%$ yield over these three steps. Treatment of $\mathbf{8 c}$ with lithium bromide in DMF afforded bromoacylsilane $\mathbf{9}$ in a $91 \%$ yield.

Free radical cyclization of acylsilane $\mathbf{9}$ using the standard tributyltin hydride method in refluxing benzene ${ }^{2}$ gave successfully the cyclized silyl ether $\mathbf{1 0}$ as a mixture of two epimers $(\mathbf{1 0 a} / \mathbf{1 0 b}=2.4$ / 1 ) in a combined yield of $77 \%$. For the sake of separation, this epimeric mixture was desilylated in a mixture of THF and methanol with catalytic amount of $p$-toluenesulfonic acid. The resulting alcohols were converted to the $p$-bromobenzoates and were separated to afford benzoates 10c (62\%) and 10d (37\%). Difference NOE experiments showed that irradiation of $\mathrm{H}(1)$ at $\delta 5.14\left(\mathrm{CDCl}_{3}\right)$ in the major isomer 10c resulted in a $4 \%$ enhancement of $\mathrm{H}(2)$ at $\delta$ 4.03. In contrast, irradiation of $\mathrm{H}(1)$ in benzoate $10 \mathrm{~d}$ at $\delta$ 5.43-5.48 did not show any enhancement of $\mathrm{H}(2)$ at $\delta$ 3.83-3.89. We therefore assigned the structure of $10 \mathrm{c}$ as having a 1,2-cis relationship of the two substituents. This stereochemical outcome indicated that in the radical cyclization step the corre-

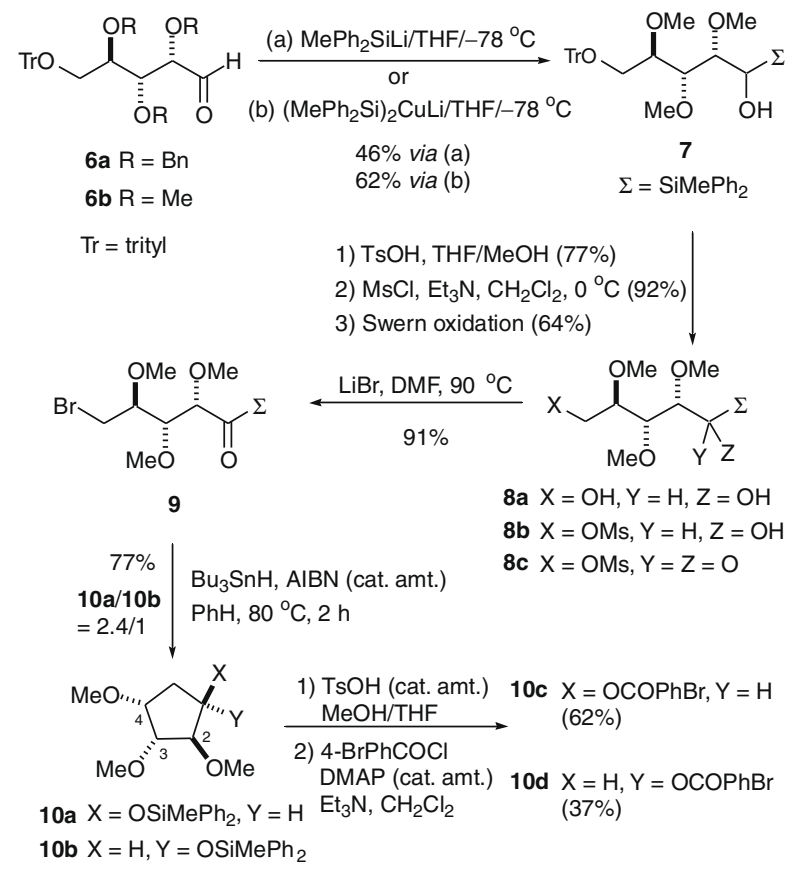

Scheme 2 . sponding $\alpha$-silyloxy cyclopentyl radical preferred to abstract a hydrogen from the face opposite to the $C(2)$ methoxy group.

As mentioned above, we attributed the lack of reactivity of alcohol 6a toward silyl anion to the steric environment around the carbonyl group. Trying to understand the origin of this steric effect, we analyzed the conformation of aldehyde $\mathbf{6 a}$. As shown in Scheme 3 , among the three staggered conformations of $\mathbf{6 a}$, the carbonyl group in conformers $\mathbf{A I}$ and $\mathbf{A I I}$ is gauche to the large group $\mathrm{R}_{\mathrm{L}}$. Conformer AIII has an all gauche relationship and presumably also made the carbonyl quite sterically encumbered. Based on this analysis, we felt that the lyxose-derived aldehyde $\mathbf{1 1}^{15}$ having a $\mathrm{C}(2)-\mathrm{C}(3)$ anti stereo-relationship would contain a low energy conformer $\mathbf{L I}{ }^{18}$ In which, the two benzyloxy dipoles are anti to each other, and the carbonyl group is anti to the large group $\mathrm{R}_{\mathrm{L}}$ but gauche to the smaller benzyloxy group. We therefore hypothesized that the carbonyl group in aldehyde $\mathbf{1 1}$ might be less sterically hindered in comparison with aldehyde $\mathbf{6 a}$.

Indeed, aldehyde $\mathbf{1 1}$ (Scheme 4) successfully coupled with the silyl cuprate and afforded diol $\mathbf{1 2}$ in 79\% yield after removal of the trityl group. Diol 12 was converted to mesylate $\mathbf{1 3}$ followed by Swern oxidation ${ }^{17}$ to give acylsilane $\mathbf{1 4}$ in $51 \%$ over two steps. Replacing the mesylate group in $\mathbf{1 4}$ with bromide using lithium bromide in DMF met with failure. However, this task was accomplished by the reaction of acylsilane $\mathbf{1 4}$ with tetrabutylammonium bromide in refluxing benzene ${ }^{19}$ and yielded bromo acylsilane $\mathbf{1 5}$ (77\%).

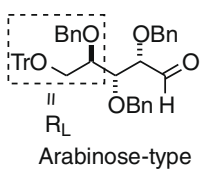

6a

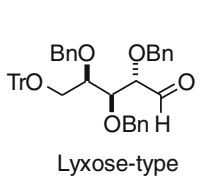

11

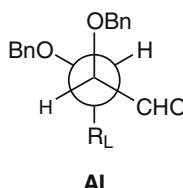<smiles>[R]C1C(Br)C(OBr)C(C=C)C1Cc1ccccc1</smiles><smiles>[R]C1C(C=O)C2C(Br)C1CC(C)C2OCc1ccccc1</smiles>

AIII
LI

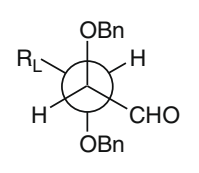

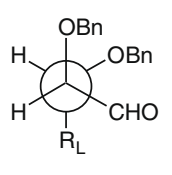

LII

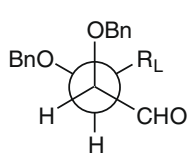

LIII
Scheme 3.

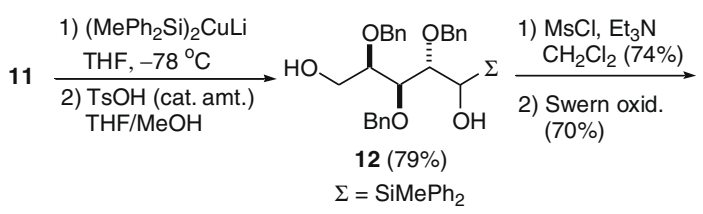

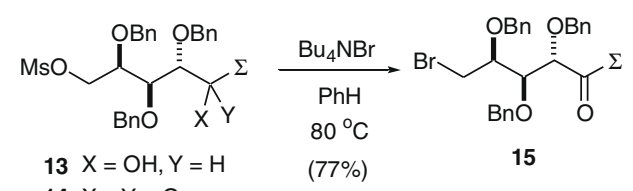

$$
14 X=Y=O
$$

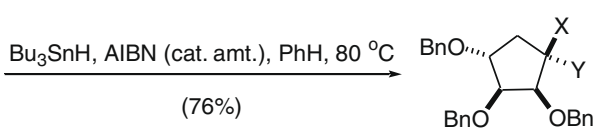

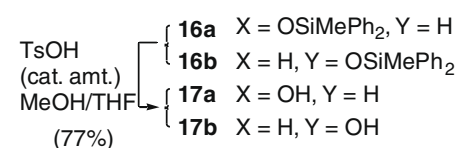

Scheme 4. 

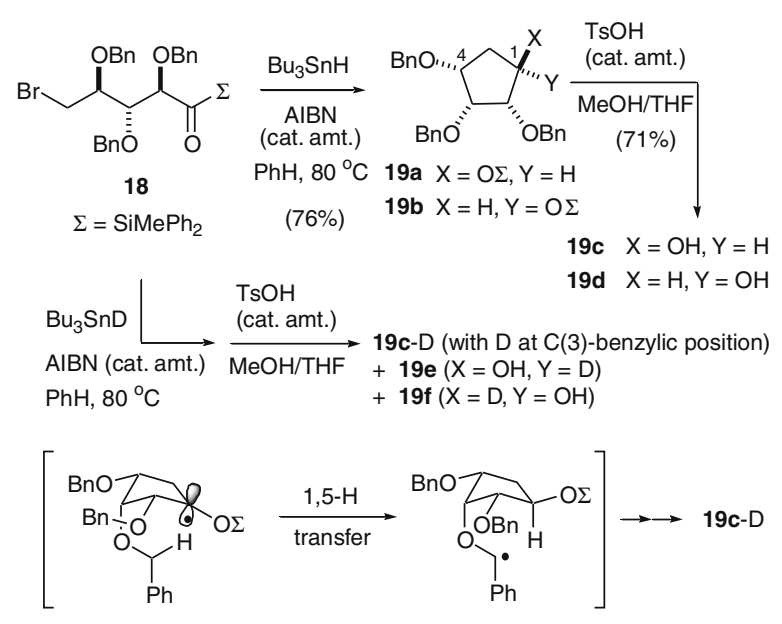

A

Scheme 5.

The tin-mediated cyclization of $\mathbf{1 5}$ was carried out successfully to give the cyclization products $\mathbf{1 6}$ in a 76\% yield with a stereoisomeric ratio of $2.8 / 1(\mathbf{1 6 a} / \mathbf{1 6 b})$. The inseparable mixture of $\mathbf{1 6}$ was desilylated to afford partially separable alcohols $\mathbf{1 7}$ (77\%). The stereochemistry of $\mathbf{1 7}$ was determined by difference NOE experiments. Specifically, irradiation of $\mathrm{H}(2)$ in cyclopentanol 17a at $\delta$ 3.94-3.99 $\left(\mathrm{CDCl}_{3}\right)$ resulted in a $16 \%$ enhancement of $\mathrm{H}(1)$ at $\delta$ 4.26-4.37. On the contrary, irradiation of $\mathrm{H}(2)$ in $\mathbf{1 7 b}$ at $\delta 3.75$ only resulted in a $4 \%$ enhancement of $\mathrm{H}(1)$ at $\delta 4.16-4.23$. These results indicated that the major isomer 17a exhibited a $\mathrm{C}(1)-\mathrm{C}(2)$ cis-relationship. Similar selectivity was also observed for the cyclization of acylsilane $\mathbf{9}$ as mentioned above.

Ribose is another pentose that exhibits a $\mathrm{C}(2)-\mathrm{C}(3)$ anti stereorelationship. Using similar methods we synthesized the D-ribosederived acylsilane $\mathbf{1 8}^{\mathbf{2 0}}$ (Scheme 5). Radical cyclization of 18 with tributyltin hydride gave a $76 \%$ yield of an inseparable mixture of cyclized products $19 \mathbf{a}$ and $19 \mathbf{b}(\mathbf{1 9 a} / \mathbf{1 9 b}=1.6 / 1)$. Removal of the silyl group then afforded alcohols 19c (43\%) and 19d (28\%). Difference NOE experiments of 19d showed that irradiation of $\mathrm{H}(1)$ at $\delta$ 4.04-4.11 $\left(\mathrm{CDCl}_{3}\right)$ resulted in a 6\% enhancement of $\mathrm{H}(2)$ at $\delta 3.43$. Conversely, irradiation of $\mathrm{H}(2)$ resulted in a $14 \%$ enhancement of $\mathrm{H}(1)$. We therefore assigned 19d as having a $\mathrm{C}(1)-\mathrm{C}(2)$ cisrelationship.

Surprisingly, the preference of stereochemical outcome in this system showed that the corresponding $\alpha$-silyloxy cyclopentyl radical abstracted a hydrogen atom from the same face relative to the benzyloxy group at $\mathrm{C}(2)$ on the cyclopentane ring. We suspected that intramolecular hydrogen abstraction might be the cause of this preference. To confirm this suspicion, the cyclization of acylsilane 18 was carried out using tributyltin deuteride followed by desilylation, and we were able to isolate alcohols $\mathbf{1 9 f}(24 \%)$ and a mixture (31\%) of 19c-D and 19e $(19 c-D / 19 e=45 / 55)$.

The complete deuteration at $\mathrm{C}(1)$ in the all-cis isomer $19 \mathrm{f}$ is obvious in the ${ }^{1} \mathrm{H}$ NMR spectrum for the disappearance of the proton signal at $\mathrm{C}(1)\left(\delta 4.10\right.$ in $\left.\mathrm{CD}_{3} \mathrm{OD}\right)$. The ${ }^{13} \mathrm{C}$ signal of $\mathrm{C}(1)$ also diminished into a very small triplet of equal intensity centered at $\delta 69.5$ (in $\mathrm{CDCl}_{3} ; J_{\mathrm{C}-\mathrm{D}}=23 \mathrm{~Hz}$ ). In contrast, in the ${ }^{1} \mathrm{H}$ NMR spectrum of the trans-cis-cis isomer mixture 19c-D and 19e, the proton signal at $\mathrm{C}(1)\left(\delta 4.36\right.$ in $\left.\mathrm{CD}_{3} \mathrm{OD}\right)$ only partially disappeared. The ${ }^{13} \mathrm{C}$ signal of $\mathrm{C}(1)$ of $19 \mathrm{e}$ appeared as a small triplet centered at $\delta$ 74.1 (in $\mathrm{CDCl}_{3} ; J_{\mathrm{C}-\mathrm{D}}=23 \mathrm{~Hz}$ ) coexisted with a signal at $\delta 74.4$ belonging to $\mathrm{C}(1)$ of $19 \mathrm{c}-\mathrm{D}$. The ${ }^{13} \mathrm{C}$ signal of the benzylic carbon ( $\delta 73.0$ in $\mathrm{CDCl}_{3}$ on the $\mathrm{C}(3)$-side chain also appeared as a singlet overlapped with a triplet indicating the incorporation of a deuterium atom at this carbon. ${ }^{21}$
Therefore, the incorporation of ${ }^{1} \mathrm{H}$ at $\mathrm{C}(1)$ in $19 \mathrm{c}-\mathrm{D}$ is most likely occurred through an intramolecular 1,5-hydrogen transfer process from the benzylic position of the $\mathrm{C}(3)$-benzyloxy group. We suggest that the $\mathrm{C}(3)$-substituent is located at a pseudo-axial position (A) and is more accessible to deliver the benzylic hydrogen to the radical at $C(1)$. Whereas the $C(4)$-benzyloxy group adopts a pseudo-equatorial position, it is difficult to reach the corresponding benzylic hydrogen for the radical.

In conclusion, we have developed a convenient way for the synthesis of acylsilanes from carbohydrate templates. All the chiral centers of the templates were conserved, and only the reducing end was transformed into acylsilane. In the meantime, the nonreducing end of the templates can be converted into a bromide. We demonstrated that these bromo acylsilanes can undergo efficient intramolecular radical cyclizations to give polyoxygenated carbocycles with different stereochemical structures. One can expect the silyloxy group to serve as a handle for the conversion of these cyclopentitols to potentially useful compounds such as aminopentitols $^{22}$ and carbocyclic nucleotides. ${ }^{23,24}$

\section{Acknowledgments}

Financial support of the National Science Council of the Republic of China is gratefully acknowledged. We are also grateful to the National Center for High-performance Computing for the computer time and facilities.

\section{Supplementary data}

Supplementary data (compound characterization data of $\mathbf{9}, \mathbf{1 0 c}$, d, 15, 17a, b, 18, 19c, and d) associated with this article can be found, in the online version, at doi:10.1016/j.tetlet.2009.04.032.

\section{References and notes}

1. For recent reviews about acylsilanes, see: (a) Ricci, A.; Degl'Innocenti, A. Synthesis 1989, 647-660; (b) Page, P. C. B.; Klair, S. S.; Rosenthal, S. Chem. Soc. Rev. 1990, 19, 147-195; (c) Cirillo, P. F.; Panek, J. S. Org. Prep. Proced. Int. 1992 24, 553-582; (d) Page, P. C. B.; McKenzie, M. J.; Klair, S. S.; Rosenthal, S. In The Chemistry of Organic Silicon Compounds; Rappoport, Z., Apeloig, Y., Eds.; John Wiley \& Sons: New York, 1998; Vol. 2, pp 1599-1665. Chapter 27; (e) Bonini, B. F.; Comes-Franchini, M.; Fochi, M.; Mazzanti, G.; Ricci, A. J. Organomet. Chem. 1998, 567, 181-189.

2. Huang, C.-H.; Chang, S.-Y.; Wang, N.-S.; Tsai, Y.-M. J. Org. Chem. 2001, 66, 89838991. and references cited therein.

3. (a) Dalton, J. C.; Bourque, R. A. J. Am. Chem. Soc. 1981, 103, 699-700; (b) Harris, J. M.; MacInnes, I.; Walton, J. C.; Maillard, B. J. Organomet. Chem. 1991, 403, C25C28; (c) Tsai, Y.-M.; Ke, B.-W. J. Chin. Chem. Soc. (Taipei) 1993, 40, 641-642; (d) Robertson, J.; Burrows, J. N. Tetrahedron Lett. 1994, 35, 3777-3780; (e) Schiesser, C. H.; Styles, M. L. J. Chem. Soc., Perkin Trans. 2 1997, 2335-2340; (f) Paredes, M. D.; Alonso, R. Tetrahedron Lett. 1999, 40, 3973-3976; (g) Paredes, M. D.; Alonso, R. J. Org. Chem. 2000, 65, 2292-2304.

4. For a recent review about Brook rearrangement, see: Moser, W. H. Tetrahedron 2001, 57, 2065-2084.

5. (a) Beckwith, A. L. J.; Hay, B. P. J. Am. Chem. Soc. 1989, 111, 230-234; (b) Beckwith, A. L. J.; Hay, B. P. J. Am. Chem. Soc. 1989, 111, 2674-2681; (c) Beckwith, A. L. J.; Raner, K. D. J. Org. Chem. 1992, 57, 4954-4962.

6. Chen, M.-J.; Tsai, Y.-M. Tetrahedron Lett. 2007, 48, 6271-6274.

7. (a) Hanessian, S. Total Synthesis of natural products: The Chiron Approach; Pergamon: New York, 1983; (b) Bols, M. Carbohydrate Building Blocks; Wiley: New York, 1996.

8. (a) Madsen, R. Eur. J. Org. Chem. 2007, 399-415; (b) Zhou, J.; Wang, G.; Zhang L.-H.; Ye, X.-S. Curr. Org. Chem. 2006, 10, 625-642; (c) Ferrier, R. J.; Hoberg, J. O. Adv. Carbohydr. Chem. Biochem. 2003, 58, 55-119; (d) Ferrier, R. J. Top. Curr. Chem. 2001, 215, 277-291; (e) Dalko, P. I.; Sinaÿ, P. Angew. Chem., Int. Ed. 1999, 38, 773-777; (f) Marco-Contelles, J.; Alhambra, C.; Martínez-Grau, A Synlett 1998, 693-699; (g) Martínez-Grau, A.; Marco-Contelles, J. Chem. Soc. Rev. 1998, 27, 155-162; (h) Ferrier, R. J.; Middleton, S. Chem. Rev. 1993, 93, 2779-2831.

9. (a) Tsang, R.; Fraser-Reid, B. J. Am. Chem. Soc. 1986, 108, 2116-2117; (b) Tsang, R.; Fraser-Reid, B. J. Am. Chem. Soc. 1986, 108, 8102-8104; (c) Tsang, R.; Dickson, J. K., Jr.; Pak, H.; Walton, R.; Fraser-Reid, B. J. Am. Chem. Soc. 1987, 109, 3484-3486; (d) Fraser-Reid, B.; Vite, G. D.; Yeung, B.-W. A.; Tsang, R. Tetrahedron Lett. 1988, 29, 1645-1648; (e) Dickson, J. K., Jr.; Tsang, R.; Llera, J. M.; Fraser-Reid, B. J. Org. Chem. 1989, 54, 5350- 
5356; (f) Yeung, B. A.; Alonso, R.; Vite, G. D.; Fraser-Reid, B. J. Carbohydr. Chem. 1989, 8, 413-427; (g) Walton, R.; Fraser-Reid, B. J. Am. Chem. Soc. 1991, 113, 5791-5799.

10. (a) Plantier-Royon, R.; Portella, C. Tetrahedron Lett. 1996, 37, 6113-6114; (b) Plantier-Royon, R.; Portella, C. Synlett 1994, 527-529.

11. Brook, A. G.; Duff, J. M.; Jones, P. F.; Davis, N. R. J. Am. Chem. Soc. 1967, 89, 431434.

12. Corey, E. J.; Seebach, D.; Freedman, R. J. Am. Chem. Soc. 1967, 89, 434-436.

13. (a) Raobo, P.; Wicha, J. J. Org. Chem. 1994, 59, 4355-4356; (b) Cirilla, P. F.; Panek, J. S. J. Org. Chem. 1994, 59, 3055-3063; (c) Cirillo, P. F.; Panek, J. S. J. Org. Chem. 1990, 55, 6071-6073.

14. Reich, H. J.; Eisenhart, E. K.; Olson, R. E.; Kelly, M. J. J. Am. Chem. Soc. 1986, 108, 7791-7800.

15. Dubost, E.; Le Nouën, D.; Streith, J.; Tarnus, C.; Tschamber, T. Eur. J. Org. Chem. 2006, 610-626.

16. Miljković, M.; Dropkin, D.; Hagel, P.; Habash-Marino, M. Carbohydr. Res. 1984 $128,11-20$

17. (a) Mancuso, A. J.; Huang, S. L.; Swern, D. J. Org. Chem. 1978, 43, 2480-2482; (b) Mancuso, A. J.: Swern, D. Synthesis 1981, 165-185.
18. For the conformational analysis of 2,3-dihalobutanes and related compounds, see: Eliel, E. L.; Wilen, S. H. Stereochemistry of Organic Compounds; John Wiley \& Sons: New York, 1994.

19. Brooks, G.; Edwards, P. D.; Hatto, J. D. I.; Smale, T. C.; Sonthgate, R. Tetrahedron 1995, 51, 7999-8014.

20. This acylsilane was synthesized from the corresponding aldehyde: Garegg, P. J. Samuelsson, B. Carbohydr. Res. 1978, 67, 267-270.

21. The ${ }^{13} \mathrm{C}$ signals of the benzylic carbons were identified through the techniques of HMQC and HMBC.

22. (a) Delgado, A. Eur. J. Org. Chem. 2008, 3893-3906; (b) Trost, B. M. J. Org. Chem. 2004, 69, 5813-5837.

23. (a) Ferrero, M.; Gotor, V. Chem. Rev. 2000, 100, 4319-4347; (b) Crimmins, M. T. Tetrahedron 1998, 54, 9229-9272.

24. (a) Ando, T.; Iwata, M.; Zulfiqar, F.; Miyamoto, T.; Nakanishi, M.; Kitade, Y. Bioorg. Med. Chem. 2008, 3809-3815; (b) Ando, T.; Kojima, K.; Chahota, P. Kozaki, A.; Milind, N. D.; Kitade, Y. Bioorg. Med. Chem. 2008, 2615-2618; (c) Siddiqi, S. M.; Jacobson, K. A.; Esker, J. L.; Olah, M. E.; Ji, X.; Melman, N.; Tiwari, K. N.; Secrist, J. A., III; Schneller, S. W.; Cristalli, G.; Stiles, G. L.; Johnson, C. R. IJzerman, A. P. J. Med. Chem. 1995, 38, 1174-1188. 